incomplete recovery in children with Guillain-Barré polyncuritis. J Pediatr 1975;86:356-59.

${ }^{3}$ Eisen A. Humphreys P. The Guillain-Barré syndrome. Arch Neurol 1974:30:438-43.

+ Asbury AK. Diagnostic considerations in Guillain-Barré syndrome. Ann Neurol 1981:9(Suppl):1-15.

${ }^{5}$ Marks HG, Augustine P, Allen RJ. Fisher's syndrome in children. Pediatrics 1977:60:726-9.
${ }^{6}$ Kibel MA. Guillain-Barré syndrome in childhood. $S$ Afr Med J 1983;63:715.

Correspondence to Dr J B McMenamin. Department of Neurology, Our Lady's Hospital for Sick Children. Crumlin. Dublin 12. Ireland.

Received 26 January 1987

\title{
Aetiology of growth hormone deficiency
}

\author{
$S$ M HERBER AND R KAY
}

Department of Paediatrics, Children's Hospital, Sheffield and the Department of Probability and Statistics, University of Sheffield

SUMMARY A retrospective analysis was performed in an attempt to identify perinatal risk factors for the development of growth hormone deficiency. More of the affected children were boys, and their birth weights were significantly lower than those of the national average; there were also considerably more preterm and post-term deliveries among boys.

The aetiology of idiopathic growth hormone deficiency ${ }^{1}$ is multifactorial and there is an increased incidence of traumatic deliveries in affected children. $^{23}$ This study was undertaken to assess whether this association exists in the United Kingdom, and to attempt to identify other perinatal risk factors.

\section{Methods}

We studied cases of idiopathic growth hormone deficiency successfully submitted to the Health Services Human Growth Hormone Committee between January 1980 and June 1984 from 18 of the 19 regional growth centres in the United Kingdom. Details of affected patients were obtained from the growth hormone request forms then in use. Information abstracted included the age and sex of the patient, date of birth, gestation, mode of delivery, birth weight, heights and ages of parents. Statistical analyses were by the $\chi^{2}$ and unpaired $t$ tests. We used the population perinatal data that were collected for the National Perinatal Epidemiology Unit in association with the Office of Population Censuses and Surveys. ${ }^{4}$ Anthropometric data were obtained from national sources. ${ }^{5}$

\section{Results}

We studied 300 children (196 boys and 104 girls). Of these, 275 children had isolated growth hormone deficiency and the remaining 25 also suffered from additional endocrine abnormalities. The mean (SD) age of boys was 10.4 (4.0) years and that of girls $9 \cdot 3$ $(4 \cdot 2)$.

No significant differences were found between affected children and the averages for the normal population concerning the heights of parents, ages of mothers or modes of delivery. The ratio of boys to girls in the sample was $1 \cdot 88: 1$, which was significantly greater than the population ratio of 1.06:1 $(\mathrm{p}<0 \cdot 001)$. The gestational age, available for 298 of the children, showed that boys with growth hormone deficiency had significantly more preterm (less than 36 completed weeks of gestation) and post-term (greater than 42 weeks of completed gestation) deliveries than the general population $(p<0.001)$; this correlation was not found in girls.

The mode of delivery was started for 287 children. We were unable to examine breech deliveries separately, as the figures for England and Wales were not collated separately and the figures for Scotland, although available, were too small for analysis. There was, however, no significant increase in the proportion of instrumental deliveries or caesarean sections in the children deficient in growth hormone.

The birth weights of 290 of the children were recorded. The mean (SD) birth weight of boys was $3.18 \mathrm{~kg}(0.63)$ and that for girls $3.15 \mathrm{~kg}(0.62)$. If we consider the children delivered at term separately the figures rise to $3.29 \mathrm{~kg}(0.51)$ and $3.20 \mathrm{~kg}(0.47)$, respectively. Compared with national figures the children deficient in growth hormone who were delivered at term were significantly lighter $(\mathrm{p}<0 \cdot 001)$. The 25 children with additional endocrine abnormalities were not significantly different from the remainder of the group. 


\section{Discussion}

This is the largest series so far to attempt to relate prenatal and perinatal factors to the subsequent development of growth hormone deficiency. The lack of any significant difference between the study group and the normal population with regard to the mode of delivery implies that the strong relation previously noted between traumatic deliveries and subsequent growth hormone deficiency no longer exists in the United Kingdom.

The higher number of boys suffering from growth hormone deficiency has been noted previously, ${ }^{1-3}$ although the ratio of affected boys to girls of 1.9:1 in this study is lower than the previous United Kingdom figure of $4: 1,{ }^{1}$ and lower than the accumulated ratio from other studies of $2 \cdot 8: 1{ }^{1}$ Growth hormone deficiency seems to be more common in boys than girls, but to what extent this is due to the fact that affected boys are more likely to seek medical attention is not clear.

As far as we know the significantly larger number of preterm and post-term deliveries in boys but not girls with growth hormone deficiency has not been described. Boys delivered preterm are more likely to suffer complications of prematurity than girls and, as cerebral hypoxia may damage the hypothalamopituitary tract, this may be another aetiological factor.

Our finding of significantly lower birth weights in children deficient in growth hormone requires further comment. Growth hormone is not thought to have an important role in fetal growth; indeed the previously described birth weights of British ${ }^{1}$ and American ${ }^{6}$ children with growth hormone deficiency were reported to be normal. The birth weights were, however, those reported by the mother rather than those obtained from birth records, and so they may not be accurate. There does not seem to be any other explanation for these findings as the heights of the parents were similar to those of the general population, and if the cause was placental insufficiency it is difficult to relate it to subsequent growth hormone deficiency. Unfortunately, birth lengths were not available: if these children had been significantly shorter than average this would have implicated growth hormone deficiency as the only aetiological agent rather than low birth weight.

We thank the directors of Growth Centres for permission to study data on their patients.

\section{References}

1 Rona RJ, Tanner JM. Aetiology of idiopathic growth hormone deficiency in England and Wales. Arch Dis Child 1977;52: 197-208.

2 Prader A, Zachman M, Poley JR, Illig R, Szeky I. Long term treatment with human growth hormone (Raben) in small doses. Evaluation of 18 hypopituitary patients. Helv Paediatr Acta 1967;22:423-40.

${ }^{3}$ Hubble D. Growth hormone deficiencies in childhood. Can Med Assoc J 1967;97:1144-58.

${ }^{4}$ MacFarlane A, Mugford M. Birth counts: statistics of pregnancy and childbirth. London: HMSO, 1984.

5 Tanner JM, Whitehouse RH, Takaishi M. Standards from birth to maturity for height, weight, height velocity and weight velocity: British children 1965. Part II. Arch Dis Child 1965;41:613-35.

${ }^{6}$ Brasel JA, Wright JC, Wilkins L, Blizzard RM. An evaluation of seventy five patients with hypopituitarism beginning in childhood. Am J Med 1965;38:484-98.

Correspondence to Dr S M Herber, Department of Paediatrics, Children's Hospital, Sheffield S10 2TH, England.

Received 15 January 1987

\title{
Neonatal lupus erythematosus, late onset hypocalcaemia, and recurrent seizures
}

\author{
A MOUDGIL, K KISHORE, AND R N SRIVASTAVA \\ Department of Paediatrics, All India Institute of Medical Sciences, New Delhi, India
}

SUMMARY A 6 day old infant had neonatal lupus erythematosus manifested by rash, haemolytic anaemia, and hepatosplenomegaly. His mother was asymptomatic until eight months of pregnancy. Between 7 and 10 weeks he had recurrent seizures with hypocalcaemia. Other causes of convulsions were excluded. By 14 weeks various abnormalities had largely disappeared.
Neonatal lupus erythematosus (NLE) is rare, about 100 cases having been reported. ${ }^{1}$ Its manifestations include rash, congenital heart block, and a variety of haematological and systemic abnormalities. ${ }^{1} \mathrm{Re}-$ cently, it has been recognised that Ro (SSA) antibodies, associated with Sjögren's syndrome, systemic lupus erythematosus (SLE), and other connective tissue diseases, are uniformly present in the blood of both infants who have NLE and their mothers who have SLE. ${ }^{1}$ This finding has led to a 